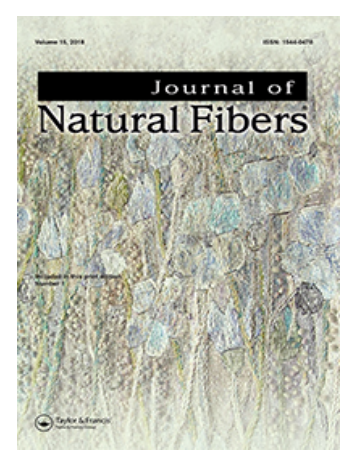

Journal of Natural Fibers

ISSN: 1544-0478 (Print) 1544-046X (Online) Journal homepage: https://www.tandfonline.com/loi/wjnf20

\title{
Effect of Thermal Aging and Chemical Treatment on Tensile Properties of Coir Fiber
}

\section{R Manjula, NV Raju, RPS Chakradhar \& Jobish Johns}

To cite this article: R Manjula, NV Raju, RPS Chakradhar \& Jobish Johns (2018) Effect of Thermal Aging and Chemical Treatment on Tensile Properties of Coir Fiber, Journal of Natural Fibers, 15:1, 112-121, DOI: 10.1080/15440478.2017.1321513

To link to this article: https://doi.org/10.1080/15440478.2017.1321513

$$
\text { 曲 Published online: } 16 \text { Oct } 2017 .
$$

Submit your article to this journal

LII Article views: 134

Q View related articles $\square$

View Crossmark data $\asymp$

4 Citing articles: 2 View citing articles 


\title{
Effect of Thermal Aging and Chemical Treatment on Tensile Properties of Coir Fiber
}

\author{
R Manjulaa, NV Raju ${ }^{a}$, RPS Chakradhar ${ }^{b}$, and Jobish Johns ${ }^{c}$ \\ aDepartment of Physics, Global Academy of Technology, Bangalore, India; 'burface Engineering Division, CSIR-NAL, \\ Bangalore, India; 'Department of Physics, Rajarajeswari College of Engineering, Bangalore, India
}

\begin{abstract}
Effect of thermal aging and chemical treatment on the physical properties of coir fiber was investigated. Coir fibers were treated with sodium hydroxide and glutaraldehyde for $2 \mathrm{~h}$. The influence of alkali and aldehyde treatment on tensile strength and elongation at break was studied in detail. Enhancement in tensile strength of coir fiber was observed up to five days of aging at $50^{\circ} \mathrm{C}$ and further decreased. Thermal cross linking of cellulose present in the fiber may be the reason for the increase in tensile strength and thermal degradation due to the chain scission of cellulose reduced the tensile strength. Sodium-hydroxide-treated samples showed an increase in tensile strength and reduction in elongation at break. The removal of impurities such as waxy and fatty acid residues from the coir fiber by reacting with strong base solution improved the strength of fiber. Cross linking of cellulose with glutaraldehyde in the fiber reduced the elasticity and enhances the strength of the material. Scanning electron microscopy was employed to analyze the change in surface morphology upon chemical treatment. Improvement in the tensile strength suggests that $\mathrm{NaOH}$ and glutaraldehyde can be effectively used to modify coir fiber with excellent physical properties.
\end{abstract}

\begin{abstract}
摘要
本文研究了热老化和化学处理对椰壳纤维物理性能的影响。在研究中, 我们用氢氧化钠和戊二醛对椰壳纤维处理 2 个小时, 并详细考察碱和醛处 理对拉伸强度和断裂伸长率的影响。在 $50^{\circ} \mathrm{C}$ 条件下老化 5 天时, 我们观察 到椰壳纤维的拉伸强度有所提高, 但之后会进一步降低。其原因可能是 纤维中存在的纤维素热交联导致拉伸强度增加, 而纤维素链断裂降低了 拉伸强度, 进而导致热降解。氢氧化钠处理的样品显示拉伸强度增加, 断裂伸长率降低。通过与强碱溶液反应从椰浆纤维中除去蜡质和脂肪酸 残留物等杂质, 可提高纤维强度。纤维素中纤维素与戊二醛的交联降低 了弹性, 但提高了材料强度。我们用扫描电子显微镜分析了化学处理后 表面形态的变化。拉伸强度的提高表明, 使用氢氧化钠和戊二醛可以有 效地对具有优异物理性能的椰子纤维进行改性。
\end{abstract}

\section{KEYWORDS}

Coir fiber; Glutaraldehyde; tensile strength; thermal cross linking

\section{关键词}

椰壳纤维; 戊二醛; 拉伸强 度; 热交联

\section{Introduction}

Glass fibers are generally used in composites which is applicable in construction, aerospace, automobile industries, etc. But glass fibers has many disadvantages-it is nonrenewable, nonrecyclable, nonbiodegradable, costly, and has high energy consumption (Wambua, Ivens, and Verpoest 2013). Natural fibers are thread-like materials which are produced by either animals or plants. This can be used for different

CONTACT Jobish Johns jobish_johns@rediffmail.com $\Theta$ Department of Physics, Rajarajeswari College of Engineering, Bangalore-560074, India.

Color versions of one or more of the figures in the article can be found online at www.tandfonline.com/WJNF. 
purposes as an alternative source for steel/synthetic fibers by increasing the strength which is done by preparing composites (Ali 2012). Plant fibers are classified according to their origin-leaf fibers (abaca, palm, pineapple, etc.), seed fibers (cotton), bast fibers (flax, hemp, and jute), fruit fibers (coir, kapok), and grass fibers (bagasse and bamboo). Plant fibers are used as potential reinforcing materials because they are abundantly available, cheap, biodegradable, low weight etc. (Kalia et al. 2011). Some studies have been carried out on the tensile and structural characterization of alkali-treated Borassus fruit fine fibers (Reddy et al. 2013). The tensile properties of Borassus fruit fibers were improved by chemical treatment using sodium hydroxide. A study on natural fibers extracted from tamarind fruits treated with alkali and further coated with polycarbonate was reported by Maheswari et al. (2012). The tensile properties of these chemically treated fibers were improved by coating with polycarbonate. Kommula et al. (2013) extracted fiber strands from Napier grass and studied the effect of alkali treatment on the physical, chemical, tensile, and thermal characteristics. Based on the enhancement in physical properties after alkali treatment, the resulting material was proposed to be a suitable fiber for the preparation of natural fiber reinforced composites.

Coconut fiber is a fruit fiber extracted from outer shell of a coconut. Coconut is a tropical fruit mainly cultivated in tropical countries such as India, Sri Lanka, Brazil, Thailand, Vietnam, Philippines, and Indonesia (Ali 2011). There are two types of coconut fiber-brown fiber extracted from mature fruit and white fibers extracted from immature fruit. Brown fiber can be used in engineering since it is mechanically strong and having high abrasion resistance. Mature brown fiber contains more lignin and less cellulose ( $\mathrm{Gu} 2009$ ).

Lignocellulosic-coir fibers are the potential biodegradable and renewable material and are used to make composites for various applications such as insulation, packaging, automobile parts, construction, etc. It is essential to do some chemical modifications to achieve better physical properties and thermal stability. It leads to improve the strength of the resulting composite material. Plant fibers generally degrade thermally through degradation, depolymerisation, and oxidation when it is heated. For example, degradation of hemicelluloses takes place at $300^{\circ} \mathrm{C}$, whereas cellulose degrades at $350^{\circ} \mathrm{C}$ and lignin degrades between $250^{\circ} \mathrm{C}$ and $600^{\circ} \mathrm{C}$ (Poletto, Júnior, and Zattera 2014). This is due to the breakdown of $\beta$-1-4-glycosidic chains from celluloses and hemicelluloses as well as cleavage of $\beta$-O4-alkyl-aryl ether linkages from lignin (Ezekiel et al. 2011).

The processing conditions have a major role to improve the mechanical properties of the composites by enhancing the interaction between matrix and reinforcements (Abraham et al. 2013; Asasutjarit et al. 2009; Brígida et al. 2010; Dixit and Verma 2012; Franco and González 2005; Khan, Alam, and Terano 2012; La Mantia and Morreale 2011; Troëdec et al. 2011). The effect of heating and aging on the mechanical properties of fibers can be studied by exposing the fibers at different temperatures before the preparation of composites. Alkali treatment is an economical method to improve the adhesivity between fiber and matrix. The strength deterioration during the alkali treatment is the main drawback (Ali 2012).

Chemical treatment using glutaraldehyde is now introduced and also included in this paper. Xiao, Xie, and Militz (2010) studied the effect of glutaraldehyde on the properties of wood. It has been reported that glutaraldehyde reduces the water uptake and moisture absorption and enhance the resistance of decay organisms because of the ability to block hydroxyl groups. Limited information is available in literature regarding the influence on physical properties of wood or plant fibers with glutaraldehyde treatment. The effect of thermal aging and chemical treatment on the tensile properties of coir fibers is studied in detail.

\section{Materials and method}

\section{Materials}

Coir fibers were procured from Central Institute of Coir Technology, Bangalore. These fibers were obtained from coconut husk of mature fruit and was extracted by process such as decorticators and 
used as received. The moisture content of the sample was about $7.74 \%$. $\mathrm{NaOH}$ pellets, $25 \%$ aqueous glutaraldehyde and phenolphthalein indicator was procured from Karnataka Fine Chem, Bangalore. The coir used for the studies has the lignin $43.61 \%$, cellulose $39.79 \%$, hemicellulose $5 \%$, pectin $0.95 \%$, and ash $3.9 \%$.

\section{Experimental}

The coir fibers were kept in a hot air oven at $50^{\circ} \mathrm{C}$ for different time intervals to study the effect of thermal aging on the stability. The alkali treatment has been done for pure fibers by immersing in $\mathrm{NaOH}$ solution. A $50 \%(\mathrm{w} / \mathrm{w}) \mathrm{NaOH}$ solution was prepared initially by dissolving 500 gm of $\mathrm{NaOH}$ in $500 \mathrm{~mL}$ distilled water. Then the coir sample was immersed in $\mathrm{NaOH}$ solution for $2 \mathrm{~h}$ and washed with distilled water to remove $\mathrm{NaOH}$ completely from the fiber. The drained water was checked for neutrality by adding phenolphthalein as an indicator. The washing was continued till there was no change in color of drained water. These fibers were dried in oven at $50^{\circ} \mathrm{C}$ for $2 \mathrm{~h}$ and introduced for tensile testing. In addition to alkali treatment, the fibers were introduced for aldehyde treatment. An aqueous solution of glutaraldehyde (25\%) was used for the chemical modification of fiber. Coir fibers were immersed in glutaraldehyde for one day and dried in oven at $50^{\circ} \mathrm{C}$ for $2 \mathrm{~h}$. Then the resulting samples were introduced for tensile testing.

\section{Tensile testing}

In order to carry out the tensile testing, the diameters of the samples were measured. Since the fiber is nonuniform, the diameter was taken from the average of five measurements. Each coir fiber was fixed to the cardboard frame using a glue tape to prevent slipping. The size of the frame was $50 \mathrm{~mm}$. About five samples were prepared from each group. The tensile testing was carried out using Instron $5500 \mathrm{R}$ Universal Testing machine. The gauge length was kept at $50 \mathrm{~mm}$ and the strain rate was set at $50 \mathrm{~mm} / \mathrm{min}$. All the aging and chemically treated samples were tensile tested. The average of five test results was taken and the standard deviation was shown in the plots.

\section{Scanning electron microscopy}

Scanning electron microscopy (SEM) was performed to investigate the morphology of the coir fibers with a TESCAN VEGA 3 LMU instrument. The surface was sputter-coated with gold before examining under the microscope.

\section{Fourier transform infrared spectroscopy}

Fourier transform infrared spectroscopy (FTIR) studies on pristine and chemically treated fibers were carried out by dispersing the powdered fiber samples on $\mathrm{KBr}$ pellets and using a Thermo Nicolet, Avatar 370 FTIR spectrophotometer. All the fiber samples were recorded in the 4000$400 \mathrm{~cm}^{-1}$ region with 32 scans in each case at a resolution of $4 \mathrm{~cm}^{-1}$.

\section{Results and discussion}

To gain some knowledge about the mechanical properties of coir fibers, stress-strain behavior was examined for unmodified, thermally aged, and chemically treated fibers. Stress-strain curves provide the information about the deformation and tensile properties of the material. Universal testing machine was employed to evaluate the tensile strength and elongation at break. The effect of aging and chemical treatment of the fiber on the tensile strength and elongation at break is studied. Stressstrain plots of thermally aged coir fibers for different time intervals are shown in Figure 1. Figure 2 shows the variation on tensile strength and elongation at break with different aging time intervals. 


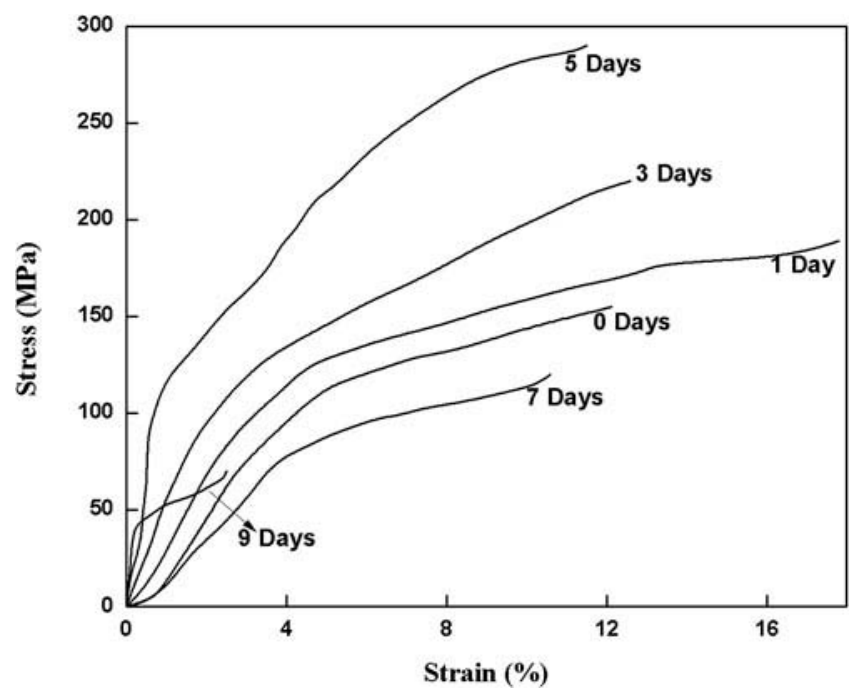

Figure 1. Stress-strain curves of unaged and thermally aged coir fibers for various days

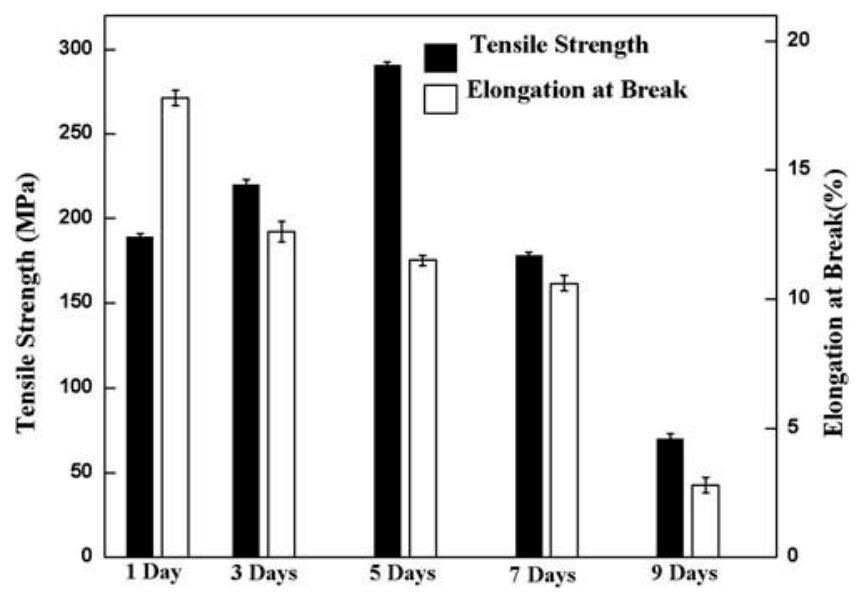

Figure 2. Variation of tensile strength and elongation at break with thermal aging.

The tensile strength of the fiber is gradually increased up to five days in hot air oven at $50^{\circ} \mathrm{C}$. This may be due to the thermal cross linking of cellulose present in the fiber. Cross linking occurs in polymers at normal temperatures. It enhances the tensile strength of the material by increasing the cross-link density. A decrease in the tensile strength is observed after five days of aging at the same temperature as shown in Figure 2. A similar behavior is observed for the modulus of thermally aged fibers (Figure 3). Modulus of the fiber aged for five days exhibited the maximum among the other aged fibers.

Thermal degradation of the constituents present in the fiber leads to reduce the tensile strength. The fiber kept in oven for five days shows the superior strength among the series of samples aged. It has been reported that cellulose undergoes cross linking during thermal aging (Kato and Cameron 1999). The thermal aging generally explained in terms of covalent cross linking and chain scission. Hydrogen bonding between adjacent chains or the formation of covalent bridges which join chains together are the two forms of thermally degraded cellulose. Formation of such type of interaction between the chains enhances the toughness and reduces the elasticity. Oxidized groups play a major role on the cross linking 


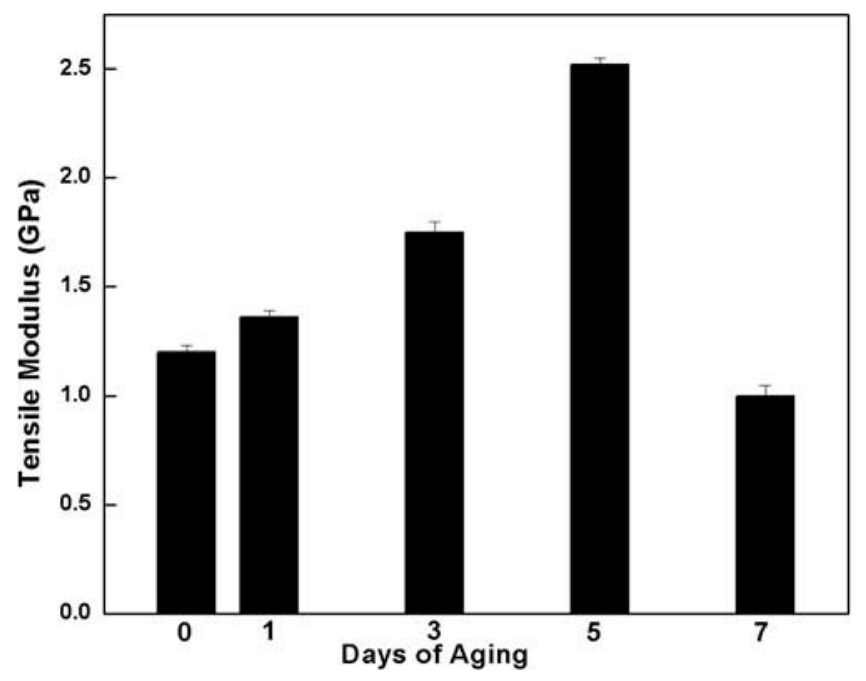

Figure 3. Variation of tensile modulus with thermal aging.

of cellulose. The presence of additional lone electron pairs on double-bonded oxygen atoms (e.g., on aldehyde, ketone, or carboxyl groups) leads to improve hydrogen bonding both within and between cellulose chains. These oxidized groups participate in reactions between the adjacent chains present in cellulose. The possible mechanism of thermal cross linking of cellulose is as shown in Scheme 1.

Elongation at break reduces with increase in aging time. Cross linking along with degradation reduces the elongation at break. Cross linking reduces the flexibility of any polymeric material. It can be concluded that the fiber aged for five days at $50^{\circ} \mathrm{C}$ exhibits excellent physical properties compared to other aged samples. The same sample can be used to prepare composites with better stability.

Coir fibers have been treated chemically with $\mathrm{NaOH}$ and glutaraldehyde separately. Stress-strain curves of untreated, $\mathrm{NaOH}$-treated, and glutaraldehyde-treated coir fibers are shown in Figure 4 . The deformation mechanism of chemically treated fibers show an entirely different manner compared to the pristine fiber. Effect of chemical modification on tensile strength and elongation at break of the fiber is shown in Figure 5. Pure fiber shows the least tensile strength and an increasing trend is observed for the chemically treated fibers. Impurities such as waxy and fatty acid residues from the coir fiber can be easily removed by reacting with strong base solution. This may be the

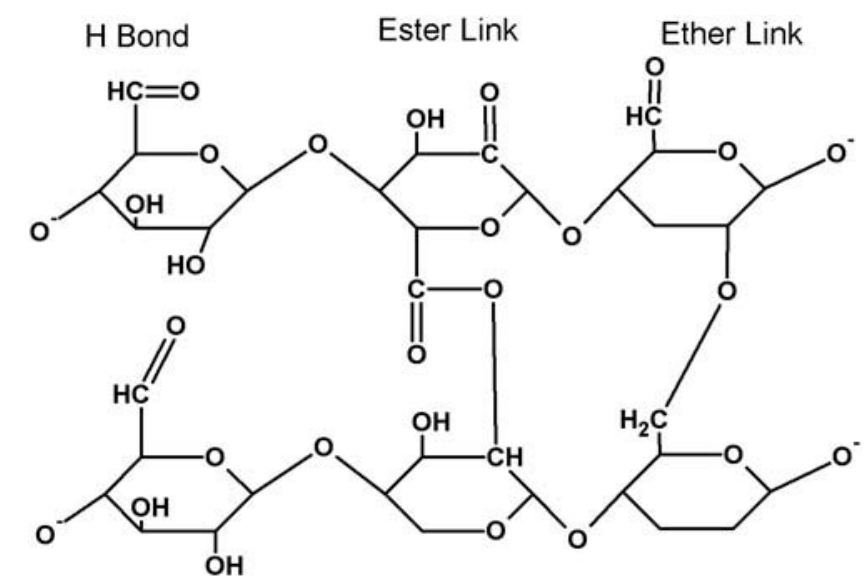

Scheme 1. Thermal cross-linking mechanism of cellulose. 


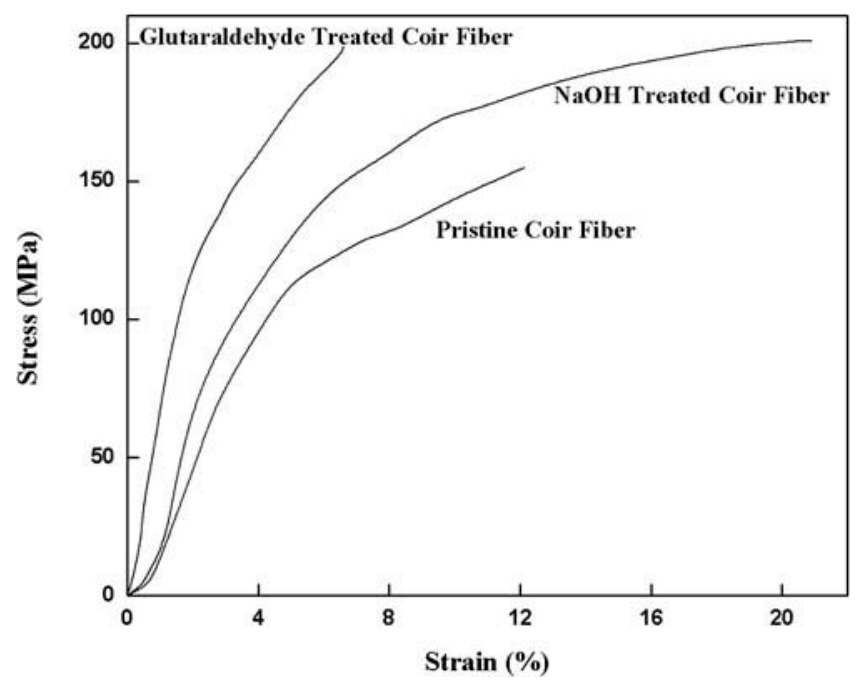

Figure 4. Stress-strain curves of pristine and chemically modified coir fibers.

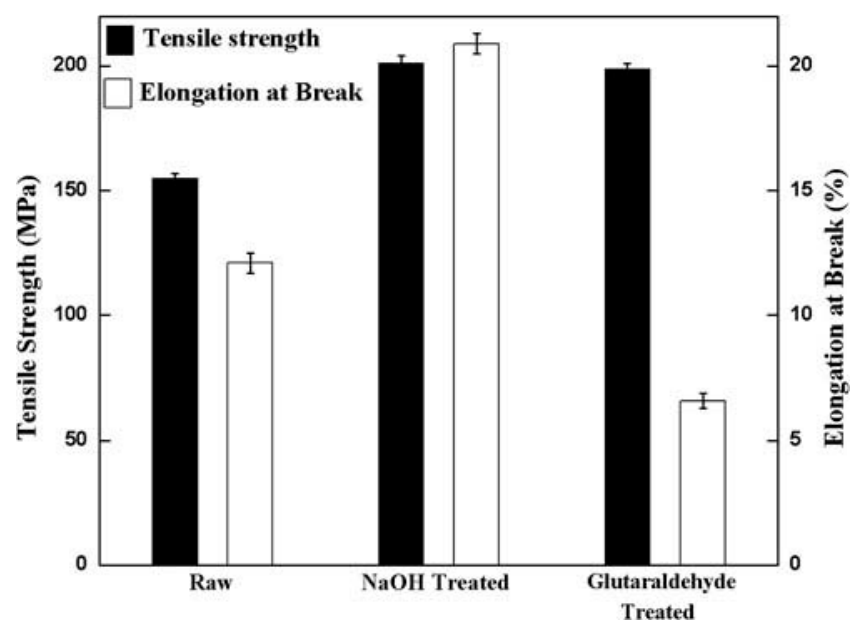

Figure 5. Variation of tensile strength and elongation at break for chemically treated coir fibers.

reason for increase in tensile strength of the fiber treated with $\mathrm{NaOH}$. Glutaraldehyde acts as a crosslinking agent for cellulose and lignin as the major constituents of coir fiber.

Aldehydes are very reactive and can be used to cross-link polymers. Cross linking occurs by reacting the hydroxyl groups of cellulose and lignin with glutaraldehyde (Distantina et al. 2013; Sen, Patil, and Argyropoulos 2015). The aldehyde forms linkages between polymer chains by reacting with the hydroxyl groups of such polymers. The cross-linking mechanism of cellulose with aldehyde is as shown in Scheme 2.

Cross linking of cellulose and lignin in the presence of glutaraldehyde enhances the tensile strength. The tensile strength values of both the chemically treated fibers are comparable. Elongation at break increases for the coir treated with $\mathrm{NaOH}$. The removal of residues from the surface increases the chain flexibility of the coir fiber and increases the capacity of elongation. There is a considerable reduction in elongation at break for the fiber treated with glutaraldehyde. Cross linking reduces the chain flexibility and makes the material more rigid. 


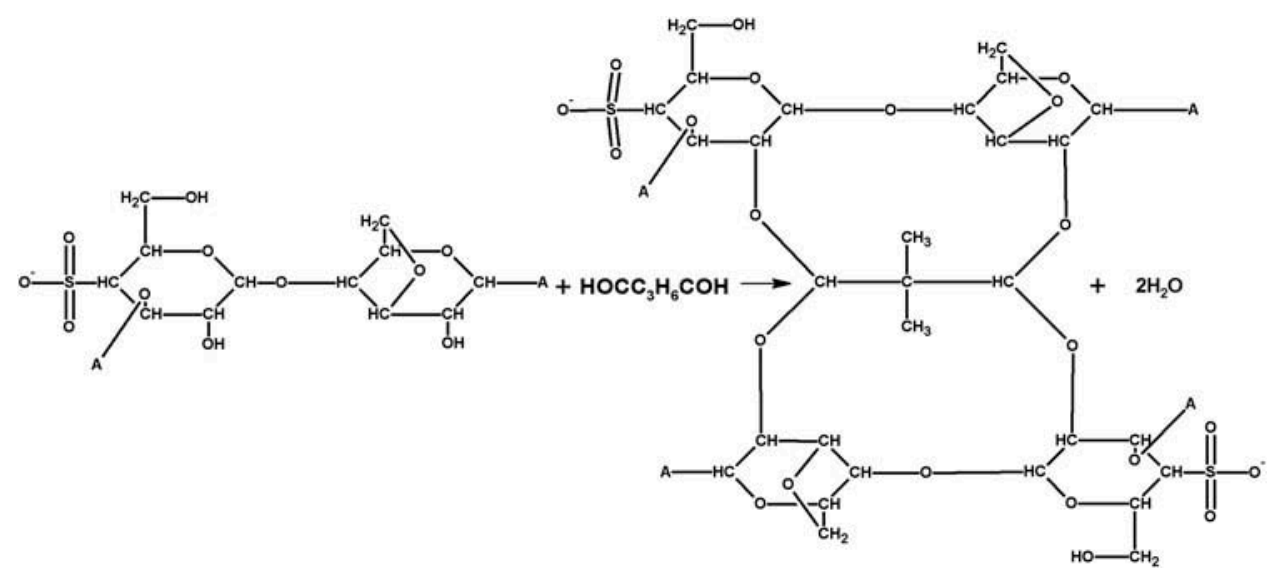

Scheme 2. Cross linking of cellulose with glutaraldehyde.

As a result, elasticity reduces by increasing the toughness of the fiber. Based on the tensile results, it can be concluded that glutaraldehyde is a suitable agent to treat coir fibers with excellent strength compared to $\mathrm{NaOH}$.

For chemically treated fibers, it is observed that the fibers treated with $\mathrm{NaOH}$, the tensile strength increased than the untreated fibers as shown in Figure 5. $\mathrm{NaOH}$ solution provides more $\mathrm{Na}+$ and $\mathrm{OH}$ - to react with the components of the fiber causing a greater amount of cellulose, lignin, pectin, and fatty acids to leach out. The fiber deformation was more for $\mathrm{NaOH}-(20.9 \%)$ treated fibers than the fibers treated with glutaraldehyde (6.6\%) as shown in Figure 5. Increase of elongation at break of coir fibers noticed after the treatment is because of the removal of impurities. The tensile modulus of pristine coir fiber is compared with the chemically treated fibers and it is shown in Figure 6. Enormous improvement in the modulus can be seen for the chemically modified samples. Therefore, the resulting chemically treated fibers can be used to prepare green composites with excellent physical properties.

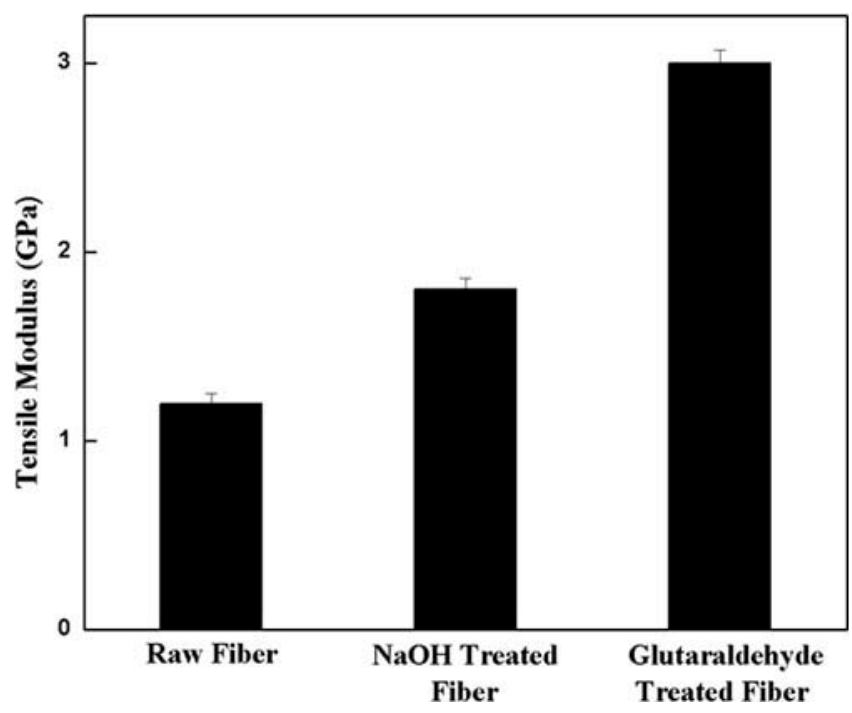

Figure 6. Tensile modulus of coir fiber and chemically treated fibers. 
The surface morphology of coir fiber before chemical treatment is shown in Figure 7a. A rough surface with irregular strips can be seen in the SEM microphotograph of uncured coir fiber. The fiber is covered with a layer of impurities including lignin. Roughened surface is observed for the coir fiber after the alkali treatment with $\mathrm{NaOH}$ (Figure $7 \mathrm{~b}$ ). Many pits are formed on the surface of alkali-treated fibers due to the removal of fatty acids, lignin, and impurities present in the fiber. It improves the interaction between fiber and matrix by the formation of mechanical interlocks when it is reinforced into the matrix for the preparation of composites. Aldehyde-treated fiber with glutaraldehyde shows a smooth surface morphology (Figure 7c). Cross-linked cellulose and lignin with glutaraldehyde enhances the smoothness of surface of the coir fiber.

FTIR spectra of untreated, $\mathrm{NaOH}$-treated, and glutaraldehyde-treated coir fibers are shown in Figure 8. Strong bands are observed at $3137 \mathrm{~cm}^{-1}, 2930 \mathrm{~cm}^{-1}$, and $2860 \mathrm{~cm}^{-1}$ corresponds to the stretching of alkyl group of cellulose as well as lignin present in the coir fiber. The band at $1110 \mathrm{~cm}^{-1}$ representing carboxyl group of fatty acids present in untreated coir fiber. In case of $\mathrm{NaOH}$-treated fibers, the peak corresponds to carboxyl group is almost disappeared. It indicates the removal of fatty acids from coir fiber by alkali treatment. The intensity of peak at $3473 \mathrm{~cm}^{-1}$ corresponds to hydroxyl group also increased for $\mathrm{NaOH}$-treated fibers. The appearance of peak at $1251 \mathrm{~cm}^{-1}$ in case of glutaraldehyde-treated fibers can be attributed to the cross-linking reaction of cellulose and lignin. This may be due to the formation of ether groups during cross linking in the presence of glutaraldehyde. The cross linking of cellulose can also be confirmed from the band $2351 \mathrm{~cm}^{-1}$ due to $\mathrm{C}-\mathrm{H}$ deformation.

Finally, it can be concluded that the chemical treatment of coir fiber with $\mathrm{NaOH}$ and glutaraldehyde is an easy method to improve the stability. The additional advantage of
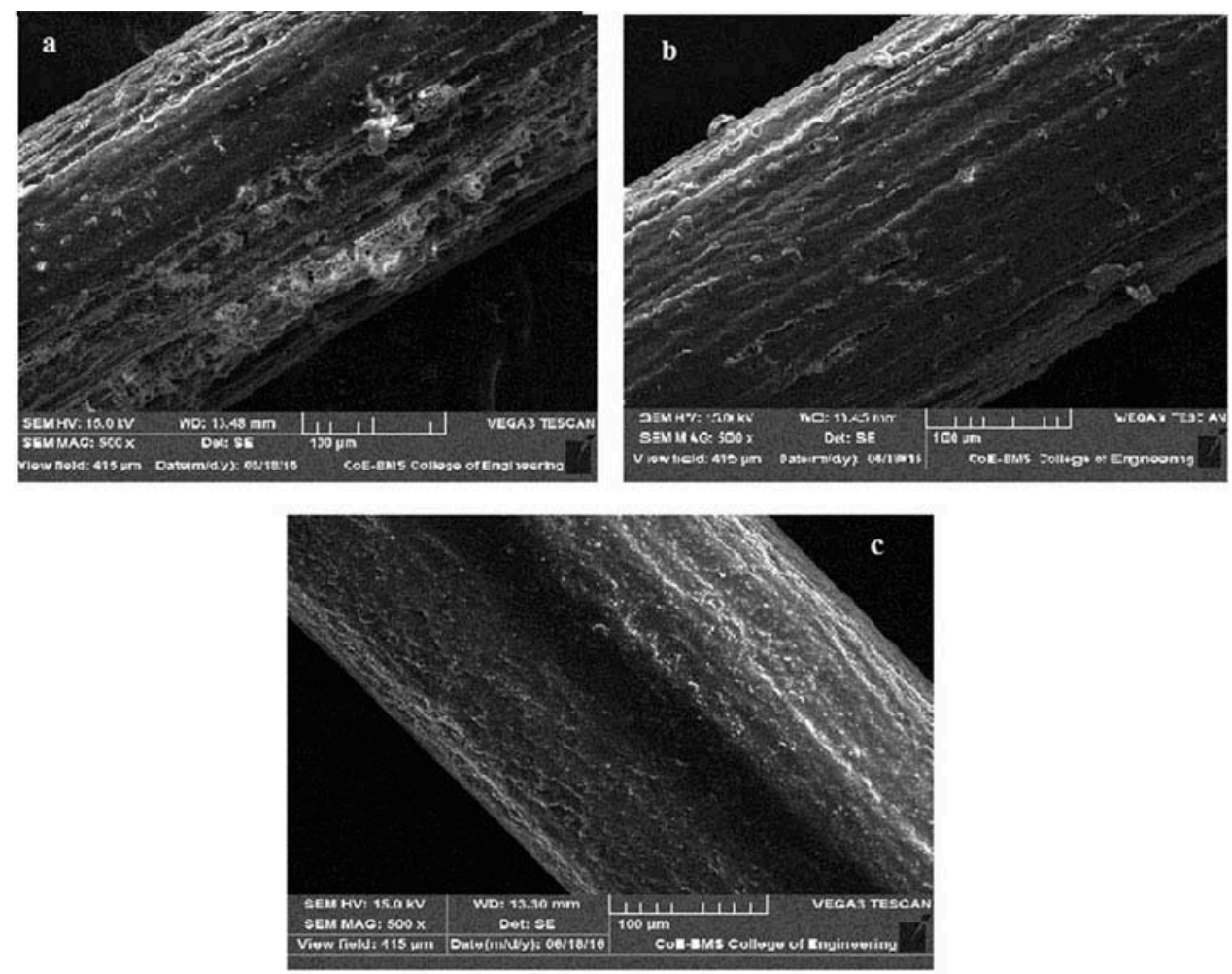

Figure 7. SEM images of (a) untreated coir fiber, (b) $\mathrm{NaOH}$-treated coir fiber, and (c) glutaraldehyde-treated fiber. 


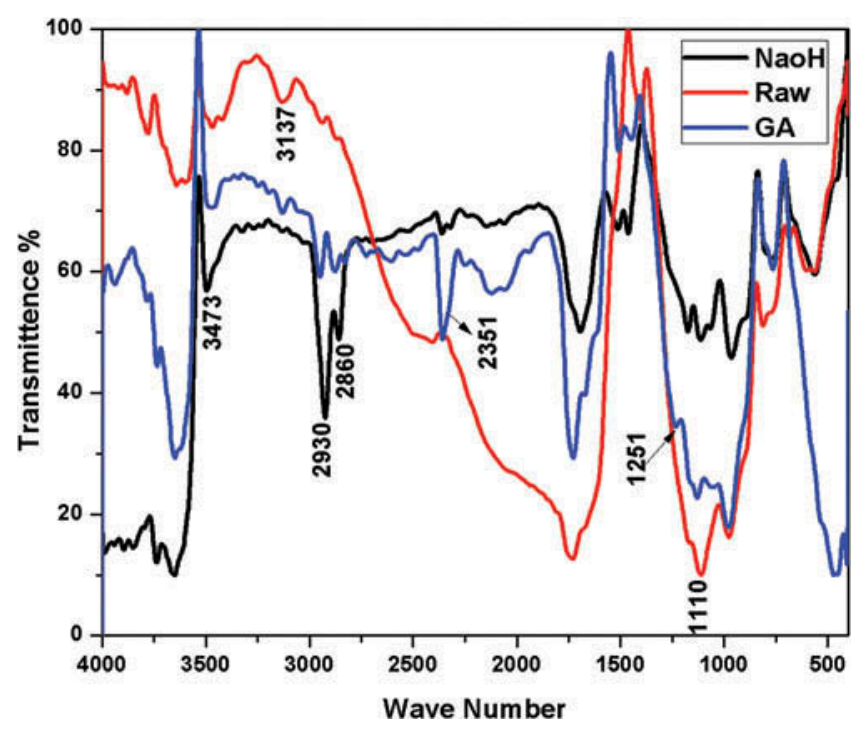

Figure 8. FTIR spectra of untreated, $\mathrm{NaOH}$-treated, and glutaraldehyde-treated coir fibers.

coir fiber is its higher elongation at break compared to other natural fibers (Bledzki and Gassan 1999; Lovely, Joseph, and Joseph 2007).

\section{Conclusions}

In this study, coir fibers were thermally aged and treated with alkali and aldehyde solutions. It was found that thermal ageing increases the tensile strength of the fiber for a certain time and further reduction occurs. The tensile properties of $\mathrm{NaOH}$ - and glutaraldehyde-treated coir samples were increased. Removal of impurities and cross linking of cellulose as well as lignin as the major constituents of coir during the above-mentioned chemical treatments increases the stability. Removal of impurities from the fiber on alkali treatment formed rough surfaces and cross linking of both cellulose and lignin on the aldehyde treatment are clearly reflected in the microphotographs of SEM. It can be concluded that such type of treatments are beneficial to improve the stability of coir fiber. In addition to this, it can be used as effective filler for the preparation of composite materials with excellent physical properties.

\section{References}

Abraham, E., B. Deepa, L. Pothen, J. Cintil, S. Thomas, M. J. John, and S. S. Narine. 2013. Environmental friendly method for the extraction of coir fibre and isolation of nanofibre. Carbohydrate Polymers 92:1477-1483. doi:10.1016/j.carbpol.2012.10.056.

Ali, M. 2011. Coconut fibre: A versatile material and its applications in engineering. Journal of Civil Engineering and Construction Technology 2:189-197.

Ali, M. 2012. Natural fibres as construction materials. Journal of Civil Engineering and Construction Technology 3:80-89.

Asasutjarit, C., S. Charoenvai, J. Hirunlabh, and J. Khedari. 2009. Materials and mechanical properties of pretreated coir-based green composites. Composites Part B: Engineering 40:633-637. doi:10.1016/j.compositesb.2009.04.009.

Bledzki, A. K., and J. Gassan. 1999. Composites reinforced with cellulose based fibers. Progress in Polymer Science 24:221-274. doi:10.1016/S0079-6700(98)00018-5.

Brígida, I. S., V. M. Calado, L. R. B. Gonçalves, and M. Z. Coelho. 2010. Effect of chemical treatments on properties of green coconut fiber. Carbohydrate Polymers 79:832-38. doi:10.1016/j.carbpol.2009.10.005.

Distantina, S., R. Rochmadi, M. Fahrurrozi, and W. Wiratni. 2013. Preparation and characterization of glutaraldehydecrosslinked kappa carrageenan hydrogel. Engineering Journal 17:57-66. doi:10.4186/ej. 
Dixit, S., and P. Verma. 2012. The effect of surface modification on the water absorption behavior of coir fibers. Advances in Applied Science Research 3:1463-1465.

Ezekiel, N., B. Ndazi, C. Nyahumwa, and S. Karlsson. 2011. Effect of temperature and durations of heating on coir fibers. Industrial Crops and Products 33:638-643. doi:10.1016/j.indcrop.2010.12.030.

Franco, P. J. H., and V. González. 2005. A study of the mechanical properties of short natural-fiber reinforced composites. Composites Part B: Engineering 36:597-608. doi:10.1016/j.compositesb.2005.04.001.

$\mathrm{Gu}$, H. 2009. Tensile behaviours of the coir fibre and related composites after $\mathrm{NaOH}$ treatment. Materials and Design 30:3931-3934. doi:10.1016/j.matdes.2009.01.035.

Kalia, S., L. Avérous, J. Njuguna, A. Dufresne, and B. M. Cherian. 2011. Natural fibers, bio- and nanocomposites. International Journal of Polymer Science 2011:1-35.

Kato, K. L., and R. E. Cameron. 1999. A review of the relationship between thermally-accelerated ageing of paper and hornication. Cellulose 6:23-40. doi:10.1023/A:1009292120151.

Khan, G. M. A., M. S. Alam, and M. Terano. 2012. Thermal characterization of chemically treated coconut husk fibre. Indian Journal of Fibre and Textile Research 37:20-26.

Kommula, V. P., K. O. Reddy, M. Shukla, T. Marwala, and A. Varada Rajulu. 2013. Physico-chemical, tensile, and thermal characterization of napier grass (Native African) fiber strands. International Journal of Polymer Analysis and Characterization 18:303-314. doi:10.1080/1023666X.2013.784935.

La Mantia, F. P., and M. Morreale. 2011. Green composites: A brief review. Composites Part A: Applied Science and Manufacturing 42:579-588. doi:10.1016/j.compositesa.2011.01.017.

Lovely, M., K. U. Joseph, and R. Joseph. 2007. Isora Fiber. Journal of Natural Fibers 3:13-27.

Maheswari, C. U., K. O. Reddy, E. Muzenda, and A. Varada Rajulu. 2012. Tensile and thermal properties of polycarbonate-coated tamarind fruit fibers. International Journal of Polymer Analysis and Characterization 17:578-589. doi:10.1080/1023666X.2012.718527.

Poletto, M., H. Júnior, and A. Zattera. 2014. Native cellulose: Structure, characterization and thermal properties. Materials 7:6105-6119. doi:10.3390/ma7096105.

Reddy, O. B., C. U. Maheswari, M. Shukla, J. I. Song, and A. V. Rajulu. 2013. Tensile and structural characterization of alkali treated Borassus fruit fine fibers. Composites Part B: Engineering 44:433-438. doi:10.1016/j. compositesb.2012.04.075.

Sen, S., S. Patil, and D. S. Argyropoulos. 2015. Thermal properties of lignin in copolymers, blends, and composites: A review. Green Chemistry 17:4862-4887. doi:10.1039/C5GC01066G.

Troëdec, M. L., A. Rachini, C. Peyratout, S. Rossignol, E. Max, O. Kaftan, and A. Smith. 2011. Influence of chemical treatments on adhesion properties of hemp fibres. Journal of Colloid and Interface Science 356:303-310. doi:10.1016/ j.jcis.2010.12.066.

Wambua, P., J. Ivens, and I. Verpoest. 2003. Natural fibres: Can they replace glass in fibre reinforced plastics. Composites Science and Technology 63:1259-1264. doi:10.1016/S0266-3538(03)00096-4.

Xiao, Z., Y. Xie, and H. Militz. 2010. Effects of modification with glutaraldehyde on the mechanical properties of wood Effects of modification with glutaraldehyde on the mechanical properties of solid wood. Holzforschung 64:475-482. doi:10.1515/hf.2010.058. 